\title{
ATTEMPTED RADICAL REMOVAL OF PARASAGITTAL MENINGIOMA: RISKS AND BENEFITS
}

\author{
Hisham H. Nofal ${ }^{1}$, Mohamed W. Samir ${ }^{2}$, Ayman A. Elshazly', Mohamed A. \\ Alwerdany ${ }^{2}$ and Hazem A. Mashaly ${ }^{2}$
}

Neurosurgery Department, Sohag Teaching Hospital, ${ }^{2}$ Neurosurgery Department Faculty of Medicine, Ain Shams University Hospital, EGYPT

Corresponding :

Hisham H. Nofal

Mobile: 1226009141

E mail:

01227896347

nofalhisham1981@yahoo.com

Received: 26/6/2019

Accepted: 31/7/2019

\begin{abstract}
Background: Parasagittal meningiomas involving the superior sagittal sinus (SSS) pose formidable obstacles to surgical management. Invasion is often considered a contraindication to surgery because of associated morbidity, such as cerebral venous thrombosis.
\end{abstract}

Aim of the work: was to evaluate the risk/benefit ratio in attempting radical excision of parasagittal meningiomas involving the superior sagittal sinus.

Patients and methods: The study consisted of 25 patients who had undergone surgery for parasagittal meningioma. Patients with meningioma involving the anterior third of the sinus underwent radical removal. Patients with meningioma that was involving the middle and posterior third of the sinus had a radical removal if the sinus was completely obliterated, and subtotal removal of tumors that are infiltrating but not obliterating the SSS.

Results: 23 patients (92\%) had radical tumor resection achieving Simpson GI and 2 patients (8\%) had subtotal tumor resection achieving Simpson GIV. There were 3 postoperative transient neurological deterioration (12\%) and 2 postoperative deaths (8\%). The recurrence rate in the study was 5\%, with a follow-up for 24 months.

Conclusion: The benefits must be carefully weighed against the risks deciding between more aggressive, radical, or less aggressive subtotal resections. The less aggressive subtotal resections if the sinus ispartially occluded may be a reasonable choice.

Keywords: Meninges, Venous Sinuses, Meningiomas, Parasagittal Meningiomas.

\section{INTRODUCTION:}

Parasagittal meningiomas are those tumors that fill the parasagittal angle, just off the midline and adjacent to the SSS and falx, with no brain tissue between the tumor and the superior sagittal sinus (SSS). ${ }^{(1)}$ Such tumors may invade partially or completely the superior sagittal sinus..$^{(2-5)}$ They comprise approximately 19.5 to $45 \%$ of all intracranial meningiomas. ${ }^{(6)}$
Parasagittal meningiomas are classified according to which third of the sinus they involve; as anterior third (from the crista galli to the coronal suture), middle third (from the coronal to the lambdoid suture), or posterior third (from the lambdoid suture to the torcular $)^{(1,5,7)}$. And they are classified by Sindou according to what extent the superior sagittal sinus is affected that guide surgical decision making and preoperative planning. ${ }^{(8-12)}$ 
Most parasagittal meningiomas as well as falcine meningiomas gain a greater clinical and surgical relevance due to their location close to the superior sagittal sinus, associated bridging veins and frequent closeness to eloquent areas, especially the tumors located in the posterior two-thirds of the superior sagittal sinus. ${ }^{(13)}$ In this case, the optimal surgical management is controversial; pose various challenges to neurosurgeons all over the world. ${ }^{(7,10,14-17)}$

The radical resection of the parasagittal meningiomas without complications is the goal of the neurosurgeon. Therefore, it is very important to preserve the venous circulation. However, the high risk of damage to the cerebral venous system and the possibility of severe neurological complications make the surgical strategy debatable. ${ }^{(18,19)}$ The advantages of a radical resection should be weighed against the potential additional risks related to the opening of the sinus and its wall resection. ${ }^{(1,20-21)}$

Some neurosurgeons consider the invasion of the middle and posterior third parts of the sinus as a contraindication for a complete resection ${ }^{(19-20)}$ and have proposed alternately more or less aggressive treatment modalities to manage this dilemma by resecting the tumor mass outside the sinus wall(s) and coagulate the remnant ${ }^{(5-6,14)}$. Other neurosurgeons consider important to perform tumor excision when the SSS is completely occluded and sufficient collateral venous pathways have been established, ${ }^{(1,14,16,22-23)}$

\section{AIM OF THE WORK}

The aim of this study was to evaluate the risk/benefit ratio in attempting radical excision of parasagittal meningiomas involving the superior sagittal sinus.

\section{PATIENTS AND METHODS}

\section{PATIENT POPULATION:}

This prospective study will include twenty five patients with a radiological diagnosis of parasagittal meningioma with variable degrees of SSS involvement who will be admitted to neurosurgery Departments of Ain Shams University Hospitals and Sohag Teaching Hospital in the period that will begin in 2014 and will end in 2018.

\section{Inclusion criteria:}

- Any patient with primary or recurrent parasagittal (falcine) meningioma.

- $\quad$ Any patient with significant mass effect and edema.

\section{Exclusion criteria:}

We excluded the cases that did not fulfill all essentials for this series like:

- Presentation of other comorbidities contraindicating surgery.

- Presentation of venous infarction with neurological deficit prior to surgery.

\section{Preoperative evaluation:}

All patients in this study will be subjected to both neurological and radiological evaluation.

\section{Neurological evaluation:}

All cases will be examined neurologically preoperative and will be rated according to the Karnofsky Performance Scale (KPS); patients will be classified into 1 of3 groups. (1) Those with normal function or minimal symptoms and can work (KPS score, 80-100); (2) those who are independent but cannot work (KPS score, 50-70); and (3) those with moderate or severe disability (KPS score, 40 and below). 


\section{Radiological evaluation:}

All patients will be evaluated using magnetic resonance imaging (MRI); pre and post contrast and magnetic resonance venography (MRV) of the brain and venous sinuses to evaluate the degree of sinus involvement.

Patients will be classified into 1 of 3 groups (1) patients with patent sinus (2) Patients with partially invaded sinus (3) Patients with totally occluded sinus; this classification determine surgical strategy.

\section{Management:}

Written informed consent will be obtained from all patients after an open discussion about the underlying disease, expected morbidity and mortality.

\section{Surgical technique:}

- $\quad$ Patient position

Patient positioning will be tailored according to the tumor location. It is crucial to position the head in a way that the meningioma is located at the uppermost part of the operative field; this provides an excellent view of the tumor and sinus with good control of blood loss and avoids unnecessary brain retraction by using the effect of gravity.

\section{- $\quad$ Surgical Incision}

When planning the size and location of the skin flap, the location of prominent scalp veins must be observed and preserved.

The incision should follow the rule of 2 $\mathrm{cm}$, which places all skin edges at least $2 \mathrm{~cm}$ away from the craniotomy. The incision extends at least $2 \mathrm{~cm}$ across the midline exposing both sides of the lesion. The base of the flap should be at least as wide as its length.

\section{- Craniotomy:}

A large craniotomy flap of sufficient extent centered over the tumor $(2$ to $3 \mathrm{~cm}$ posterior and 2 to $3 \mathrm{~cm}$ anterior to the tumor boundaries) will be performed crossing the midline to permit visualization of both sides of the sinus.

- Dural opening:

A semilunar dural flap will be based along the SSS; taking care not to compromise the adjacent bridging veins to the sinus. Remove any dura that has been invaded along with the tumor.

- Tumor Resection:

Tumor resection will start as follows:

1- Devascularization of the tumor: the attachment of the meningioma to the lateral wall of the sinus will be detached by using the cutting mode of the bipolar coagulation forceps.

2- Internal tumor debulking: working inside the meningioma by piecemeal tumor excision, so that the remaining capsule of the tumor can be easily mobilized without brain retraction.

3- Sharp dissection of the arachnoid plane: freeing the capsule from the brain tissue by identifying the layer of arachnoid at the brain-tumor interface which is sharply cut with microscissor.

Superior sagittal sinus surgical strategy:

The strategy of the operation depends on the status of the superior sagittal sinus (SSS).

\section{- Patent sinus:}

The attachment of the tumor to the SSS will be coagulated with bipolar forceps and will be peeled until a clean, shiny dural surface will be obtained, and the sinus will be preserved.

\section{- $\quad$ Totally occluded sinus:}

"en-bloc" resection of the meningioma will be done. The dura will be opened bilaterally in a butterfly fashion based on the SSS. The sinus will be palpated anterior and 
posterior to the invaded occluded part, transfixing stitches through the falxcerebri will be placed and the sinus will be resected with preservation of the collateral venous channels

\section{- Partially occluded sinus:}

The strategy of surgery will depend on the site of occlusion along the SSS:

\section{Partially occluded anterior third of the $\underline{S S S}$}

We will resect the sinus wall for removal of the intraluminal fragment then we will repair the dural defect by suturing or by closing it with a patch of galeacapitis or pericranium.

Partially occluded posterior two thirds of the SSS

We prefer subtotal tumor excision; preserving the sinus intact; leaving the intraluminal fragment. The outer leaf of the dura mater will be cauterized extensively with a bipolar cautery.

\section{- $\quad \underline{\text { Closure }}$}

We will do duroplasty by pericranial graft and will be closed in watertight fashion.

\section{Postoperative care:}

Radiologic studies will be performed within 24 hours after the operation. A CT scan with contrast and/or a MRI will be performed to look for a tumor remnant, to assess the extent of resection and immediate postoperative complications.

\section{Follow up:}

We will follow up the cases for at least 24 months clinically and radiologically.

- $\quad$ Radiological follow up:

In normal course of the cases we will requestMRI Brain pre- $\&$ post contrast plus MRV after three months then every 6months interval for the first 2 years to detect any recurrence.
- $\quad$ Clinical follow up:

Evaluation of the patients clinically will be performed, and they will be rated according to the Karnofsky Performance Scale (KPS); imaging studies will be requested if there will be any neurological deterioration.

\section{RESULTS}

\section{Patient Characteristics:}

25 patients had parasagittal (falcine) meningioma underwent surgical tumor resection in the period that began in 2014 and ended in 2018. The patients ranged in age from 28 to 82 years (mean, 53.2 years). There were 14 male $(56 \%)$ and 11 female (44\%). two patients had undergone surgery previously. Time to follow-up was at least 24 months. Three patients could notbe contacted and were lost to follow-up.

\section{Tumor Characteristics:}

In the majority of cases (18 patients, $72 \%$ ), the location of the tumor was the middle third of the sagittal sinus. the anterior third of SSS was involved in 4 patients $(16 \%)$, the posterior third in 3 patients $(12 \%)$. The SSS was patent in 14 patients $(56 \%)$, partially occluded in 3 patients $(12 \%)$, and totally occluded in 8 patients $(32 \%)$

\section{Tumor Resection}

Twenty-three patients (92\%) had radical tumor resection achieving Simpson grade I resection (Fig.1) and two patients (8\%) with partially occluded posterior third in whom total tumor removal would have required sacrificing the sinus, we decided to resect the tumor subtotally only the extrasinusal portion without interrupting sinus patency achieving Simpson grade IV (Table 1). 
Fig. (1) Intraoperative photo showing macroscopic radical resection of the tumor.

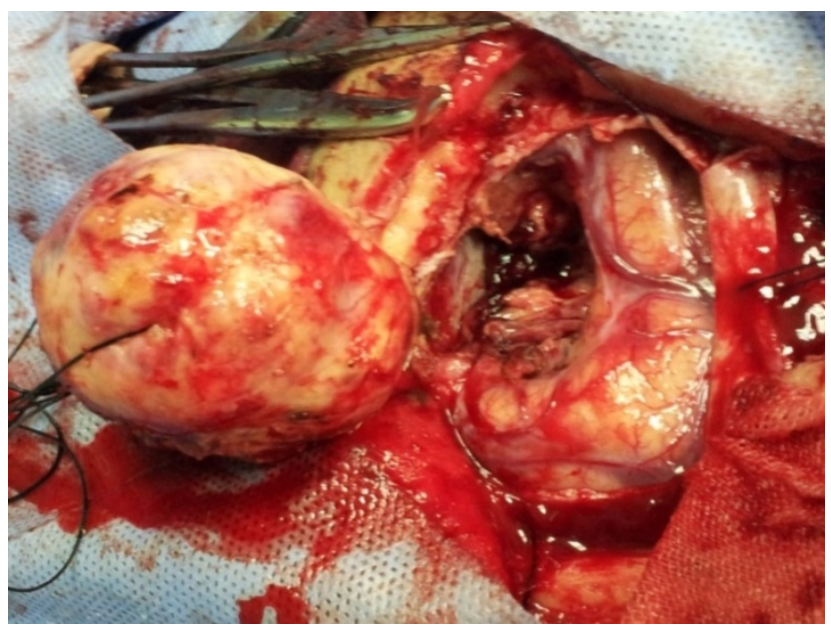

Table (1): Tumor resection in relation to status of SSS

\begin{tabular}{|c|c|c|c|c|c|c|}
\hline \multicolumn{3}{|c|}{ Variables } & \multicolumn{3}{|c|}{ Status of SSS } & \multirow[t]{2}{*}{ Total } \\
\hline & & & \multirow{2}{*}{$\begin{array}{c}\text { Patent } \\
14\end{array}$} & \multirow{2}{*}{$\begin{array}{c}\text { Partially } \\
\text { Occluded } \\
1\end{array}$} & \multirow{2}{*}{$\begin{array}{c}\begin{array}{c}\text { Totally } \\
\text { Occluded }\end{array} \\
8\end{array}$} & \\
\hline \multirow{4}{*}{$\begin{array}{l}\text { Tumor } \\
\text { Resection }\end{array}$} & \multirow[t]{2}{*}{ Radical } & Count & & & & 23 \\
\hline & & $\%$ of Total & $56.0 \%$ & $4.0 \%$ & $32.0 \%$ & $92.0 \%$ \\
\hline & \multirow[t]{2}{*}{ Subtotal } & Count & 0 & 2 & 0 & 2 \\
\hline & & $\%$ of Total & $0.0 \%$ & $8.0 \%$ & $0.0 \%$ & $8.0 \%$ \\
\hline \multirow{2}{*}{\multicolumn{2}{|c|}{ Total }} & Count & 14 & 3 & 8 & 25 \\
\hline & & $\%$ of Total & $56.0 \%$ & $12.0 \%$ & $32.0 \%$ & $100.0 \%$ \\
\hline
\end{tabular}

There was a statistically significant relationship between tumor resection and status of SSS by Fisher's exact test (P-value $=0.01<0.05)$

\section{Histopathological findings}

Tumors were classified and divided into histological subtypes according to World Health Organization (WHO) criteria (table2)

Table (2): Histopathological classification of 25 patients with parasagittal meningioma according to WHO grading

\begin{tabular}{|c|c|c|c|}
\hline Pathology & Number of patients & Percentage & WHO grading \\
\hline Meningothelial & 9 & $36.00 \%$ & GI \\
\hline Fibroblastic & 3 & $12.00 \%$ & GI \\
\hline $\begin{array}{c}\text { Mixed transitional } \\
\text { and fibroblastic }\end{array}$ & 3 & $12.00 \%$ & GI \\
\hline Psammomatous & 5 & $20.00 \%$ & GII \\
\hline Atypical & 5 & $20.00 \%$ & \\
\hline
\end{tabular}

\section{Postoperative morbidity and mortality}

Overall, morbidity occurred in 3 patients $(12 \%)$; transient neurological deterioration due to brain swelling occurred in patients with middle third SSS meningiomas. Two of them had totally occluded sinus and one patient had patent sinus. In all of them, the tumor had been removed through radical resection. All of these patients recovered from their complications within few days by corticosteroid and osmotic diuretic use. 
Two patients (8\%) died during the postoperative period, one secondary to postoperative brain swelling and one because of myocardial infarction.

\section{Neurological outcome:}

Early postoperative analysis of functional status in our patient group demonstrates (2 patients; $8 \%$ ) were died, (3 patients; $12 \%$ ) had mild transient worsening of their preoperative status, and most patients improved or remained unchanged (20 patients; $80 \%$ ).

All living patients were examined neurologically for functional statusearly postoperative and 3 to 6 months after surgery and were rated according to the Karnofsky Performance Scale (KPS)(table 3\& Fig.36);

Table (3): Comparison of preoperative neurological functional status with neurological outcome of living patients at early and late postoperative period

\begin{tabular}{|c|c|c|c|}
\hline Neurological functional status & Preoperative & Early Postoperative & Late Postoperative \\
\hline KPSscore, $80-100$ & $32 \%$ & $43.5 \%$ & $95 \%$ \\
\hline KPS score, $50-70$ & $52 \%$ & $47.8 \%$ & $5 \%$ \\
\hline KPS score, 40 and below & $16 \%$ & $8.7 \%$ & - \\
\hline
\end{tabular}

There was a statistically significant relationship between preoperative, early postoperative, and late postoperative

Diagram (1): Comparison of preoperative neurological functional status with neurological outcome of living patients at early and late postoperative period.

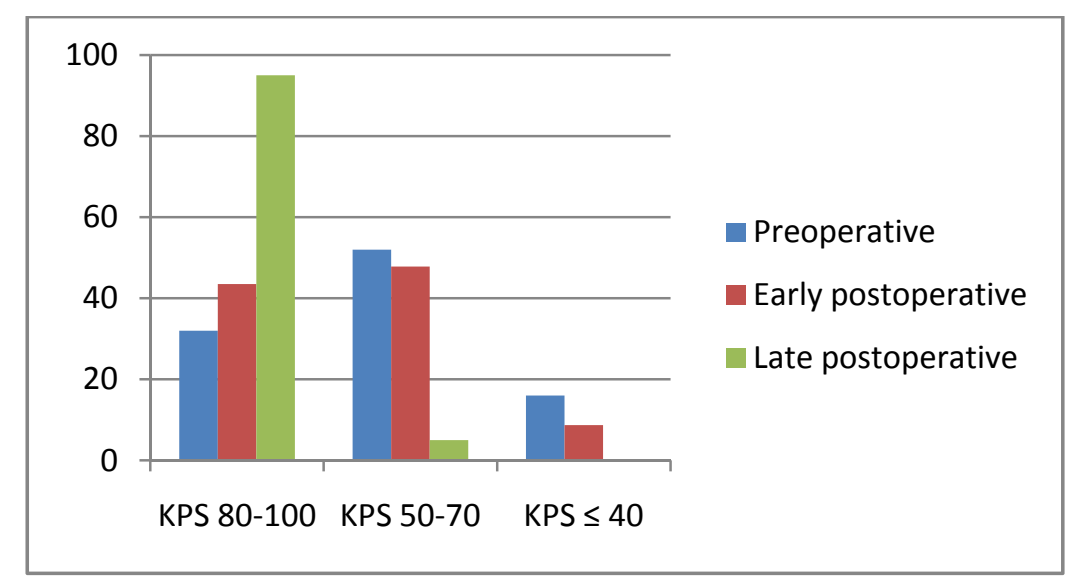

\section{Recurrence Rate:}

Clinical and radiological follow up for at least 24 months revealed only one patient $(5 \%)$ had a tumor recurrence after 18 months; the histopathological diagnosis was" atypical meningioma" WHO GII.

\section{Statistical analysis}

Data was analyzed using Statistical Package for Social Science (IBM SPSS statistics) package version (24), and Epicalc (2000) package.Friedman test was used to compare between more than two dependent variables via their mean rank, Chi-square test or Fisher exact test were used to investigate the statistically significance relationship between variables. Also, Chisquare test was used to detect whether there was a statistically significance differences between the percentages of the variables or not, i. e., P-value as considered significant if it was less than 0.05 .

\section{Illustrative Case}

A 28 years old male patient presented with paraparesis that had been present for 2 
months, andhad several episodes of generalized seizures and behavioral changes for 6 months. Neurological examination revealed bilateral lower limbs hyperreflexia, and bilateral positive Babinski sign. Preoperative imaging with MRI brain revealed a bilaterally parasagittal frontoparietal lesion with homogeneous dense enhancement following contrast infusion invading the anterior third of the sagittal sinus (Fig.3). MRV demonstrated segmental obstruction of the anterior third of sinus with formation of perilesional collateral venous channels (Fig.4). The bicoronal skin incision is performed up to the dermis.Bilateral craniotomy flap was performed centered over the tumor. The dura was opened bilateral in a butterfly fashion based on the SSS. The attachment of the meningioma to the lateral wall of the sinus was detached by using the cutting mode of the bipolar coagulation forceps, thus cutting off the tumor dural supply. Then the tumor was debulked by piecemeal tumor excision, so that the tumor can be easily mobilized from the underlying cortex without brain retraction then sharp dissection of the arachnoid plane for freeing the capsule from the brain tissue with microscissor. Wet cottonoid strips are applied in this plane continuously till complete tumor removal until the falx was clearly visible. The sinus was palpated anterior to and posterior to the invaded occluded part, transfixing stitches through the falx cerebri were placed and the sinus was resected with preservation of the collateral venous channels (Fig.5). The tumor was totally removed with the infiltrated dura achieving Simpson grade I resection.No intraoperative or postoperative complications were encountered. An immediate postoperative CT brain was done revealed no residual lesion. Postoperatively, paraparesis improved gradually over 6 weeks. The histopathological diagnosis was "Atypical meningioma" (WHO grade II). A follow up MRI brain with intravenous contrast was performed at the third month postoperatively revealed complete removal of the lesion with no recurrence (Fig.6).
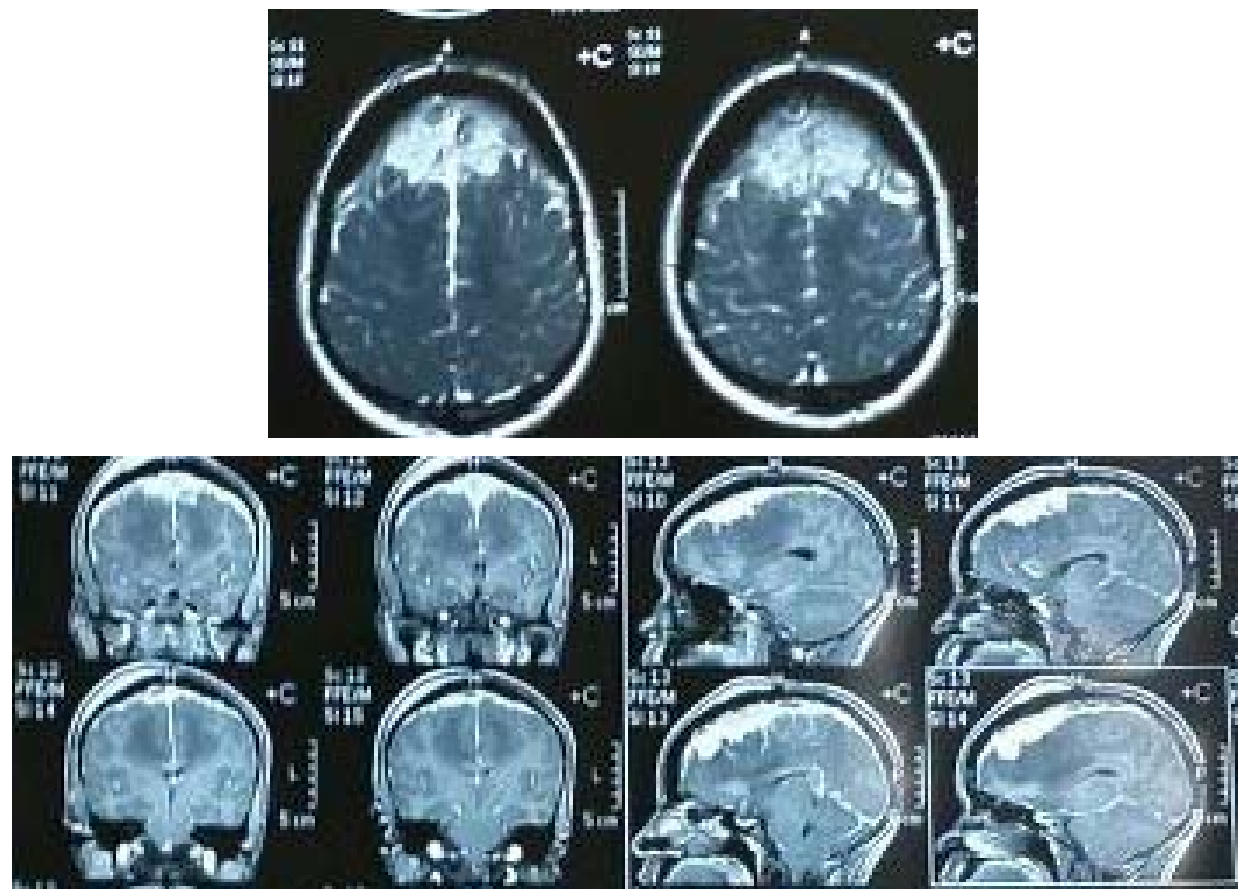

Fig. (2): Preoperative brain MRI in axial, coronal, and sagital T1 weighted images with gadoliniumn revealed a bilateral parasagittal extra-axial tumor, with a homogenous enhancement at the anterior third of the superior sagittal sinus. 


\section{Hisham H. Nofal, et al.,}

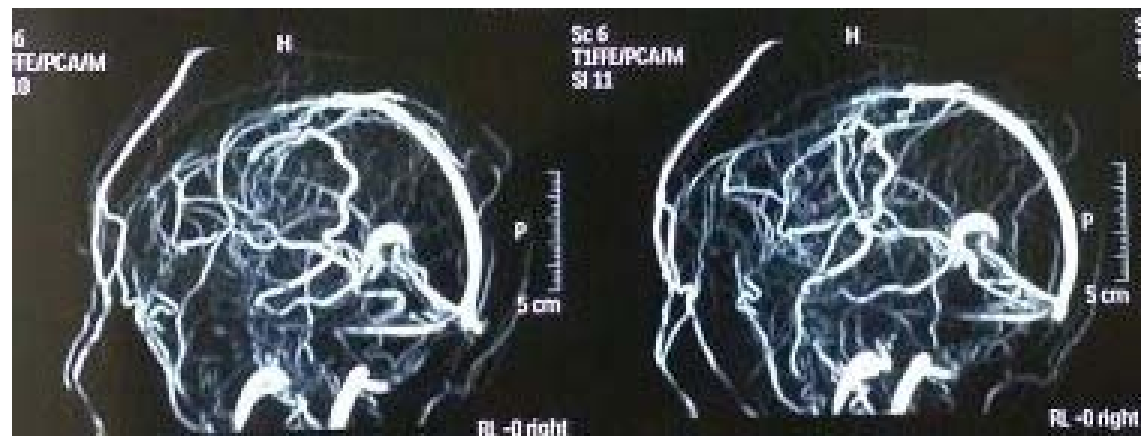

Fig. (3): Preoperative MRV, lateral view, showing total occlusion of the anterior third of the sinus and compensatory collateral vessels through intra-osseous emissary veins.

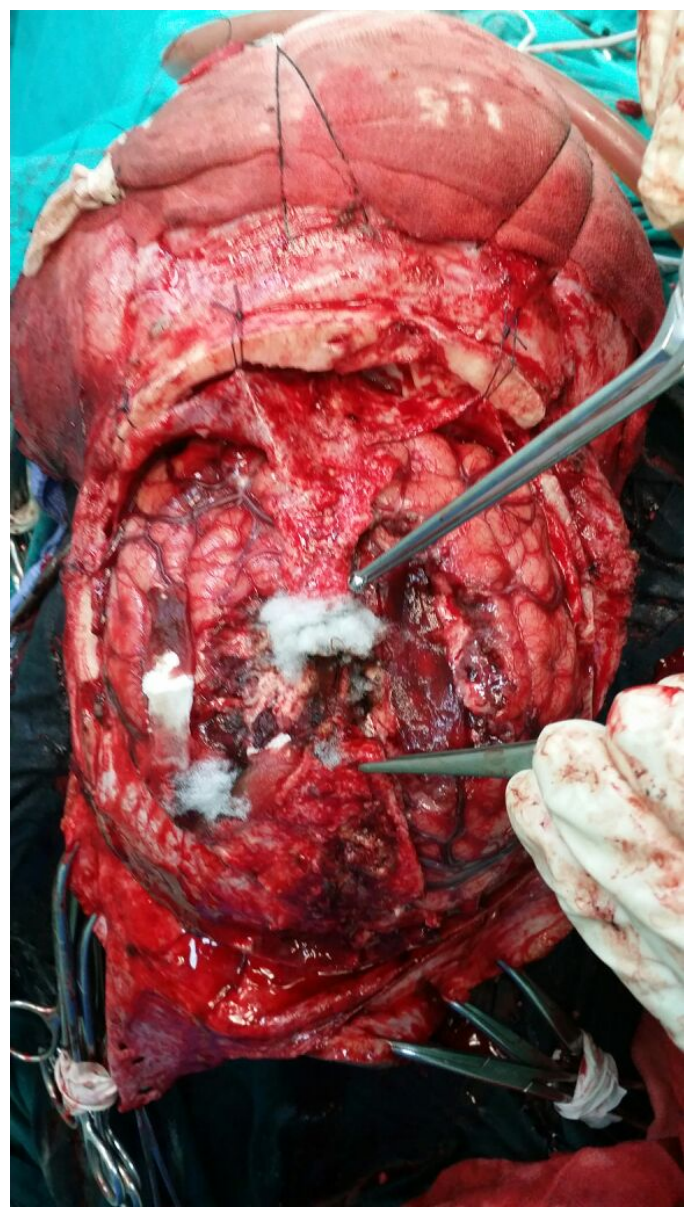

Fig.(4): Intraoperative photo showing the sinus exposure and the bilateral dural opening. The tumor was completely removed and the tumor bed. Transfixing stitches through the falx cerebri were placed and the sinus was resected. 

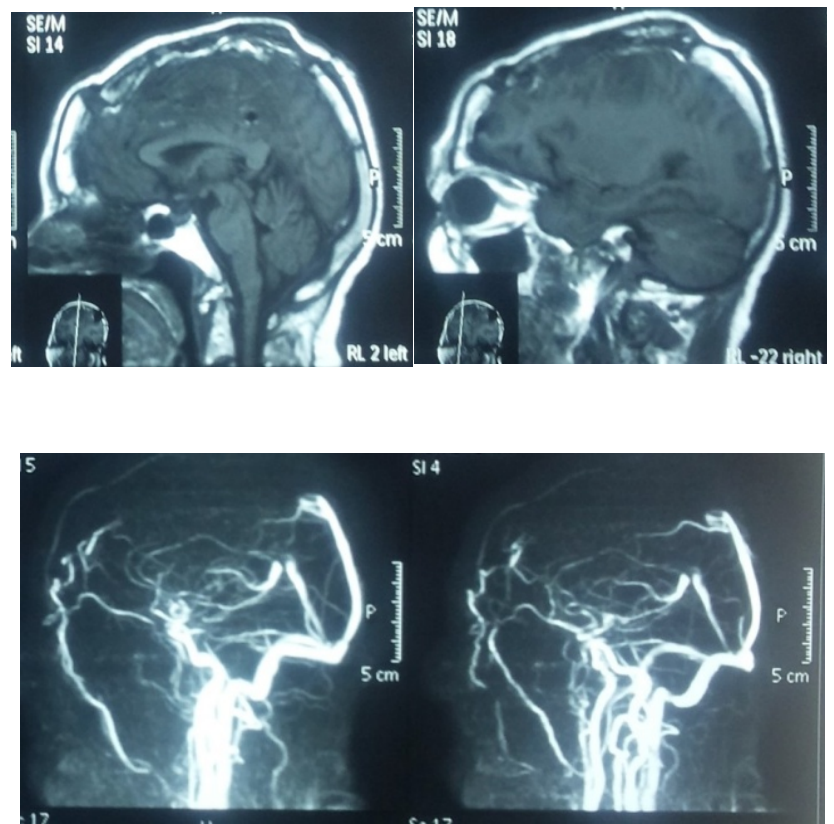

Fig. (5): $3^{\text {rd }}$ month postoperative MRI brain in sagittal T1 weighted images with gadolinium and MRV showing complete removal of the lesion.

\section{DISCUSSION:}

Despite technical advances, surgical removal of parasagittal meningiomas represents a surgical challenge to neurosurgeons, mainly because of their intimate relationships with the sagittal sinus and bridging veins. The neurosurgeon should balance aggressive surgery to achieve radical resection with preservation of venous flow that is the major cause of postoperative morbidity and mortality. ${ }^{(14,24-27)}$

The radical resection of parasagittal meningiomas without complications and recurrences is the goal of the neurosurgeon. ${ }^{(19)}$

Sindou et al (8-11) reported that meningioma invading the superior sagittal sinus, present the surgeon with dilemma of whether to 1) leave the fragment invading the sinus, thus creating high risk of recurrence or 2) attempt total removal with or without venous reconstruction and expose the patient to a potentially greater operative danger.
Radical removal can be done if the sinus is totally occluded, it is ligated at the proximal and distal ends of the involved sinus and then resected, allowing en bloc tumor removal without significant risks. ${ }^{(27-}$ 28)

Ricci et al and Huo et al., reported that radical resection of the tumors with the obstructed segment of the SSS was safe without the need for SSS reconstruction as the collateral venous pathways developed during the progressive course of the disease. ${ }^{(19,29)}$

Lesions that partially occlude the sinus without collateral pathways are at particular risk for complications suggesting a more conservative treatment aimed at resecting only the extrasinusal portion of the meningioma while preserving major cortical veins, and leaving tumor remnants that significantly involve the sinus and awaiting for sinus occlusion by residual tumor with the hope of promoting the development of collateral venous outflow. $(5,7,14,24,30,31)$

This strategy was agreed and reported by Colli et al in their series, they opted to 
perform a subtotal resection when the posterior two thirds of the sinus was significantly invaded by a tumor and they never interrupted and reconstructed the sinus. ${ }^{(7)}$

Sughrue et al. postulated that the residual small tumor portion which invades SSS will not increase in short period even without adjuvant radiation-based treatments. Because the most common histopathological grade was benign one and ifit happened they prefer to shift to radiotherapy ${ }^{(30)}$.

Our management paradigm has been to achieve Simpson grade I resection but with the goal of preservation of venous structures. Support for this paradigm is highlighted by the lower morbidity, mortality and comparable recurrence rate in our series in comparison with the literature highlighted by previously published data indicating recurrence even in the face of Simpson grade I resection. Our study demonstrated that the most significant and prevalent complication is short term neurological deterioration due to cerebral venous thrombosis/infarction(12\%), and long-term recurrence rate of $(5 \%)$. These results raise the importance of understanding risk factors for operative complications in addition to factors influencing recurrence and underlying treatment paradigms.

In the study of Tomasello et al which conducted on 67 patients aiming at attempted radical removal of parasagittal meningioma, where $(5 \%)$ developed venous infarction. ${ }^{(32)}$

Sughrue et al postulated that the majority of the recurrences that they observed resulting from higher-gradetumor histopathological features. ${ }^{(30)}$

The low incidence of recurrence in our series is due to the longer period of follow up in other studies. Our mean follow up period was 24 months as compared to longterm 25-year follow-up of surgically treated parasagittal meningiomas by Segerlind et al. ${ }^{(15)}$

In light of these considerations, our management strategy primarily consists of attempts at Simpson grade I resection without sacrifice of critical vascular structures. Even if the resection is subtotal, the residue can remain stable for years. If regrowth occurs, it may be a few millimeters per year with a progressive evolution of the collateral circulation and progressive sinus thrombosis.

\section{$\underline{\text { Conclusion }}$}

The benefits must be carefully weighed against the risks deciding between more aggressive, radical, or less aggressive subtotal resections. The less aggressive subtotal resections if the sinus is partially occluded may be a reasonable choice.

\section{REFERENCES}

1. Mantovani A., Ferreira M., da silva H. B., et al. (2016): Parasagittal and Peritorcular Meningiomas, Atlas of Neurosurgical Techniques, Sekhar L. N. and Fessler R. G. (eds.), $2^{\text {nd }}$ ed., volume2, section I Brain Tumor; 7:54-80.

2. Hancq S., Baleriaux D. and Brotchi J. (2003): Surgical Treatment of Parasagittal Meningiomas, Seminars in Neurosurgery; 14(3):203-210.

3. Pradilla G., Solero C.L. and DiMeco F. (2011): Parasagittal Meningiomas, AlMefty's Meningiomas, 2nd ed., DeMonte F., McDermott M. W. and Al- Mefty O. (Eds.); 16: 142-160.

4. Wang S., Ying J., Wei L., et al. (2015): Effects of parasagittal meningiomas on intracranial venous circulation assessed by the virtual reality technology, Int J ClinExp Med; 8(8):12706-12715.

5. Papacocea T., Mladin A. and Papacocea A. (2017): Parasagittal meningiomas literature review and a case report, J Clin Invest Surg.; 2(1): 39-44. 
6. Lynch J.C., Schiavini H., Bamfim C., et al. (2013): Microsurgical resection for parasagittal meningiomas with preservation of the parasagittal sinus and excellent neurovascular control, ArqNeuropsiquiatr; 7(5):301-306.

7. Colli B.O., Carlotti C.G., Assirati J.A., et al. (2006): Parasagittal meningiomas: followup review, Surgical Neurology; 66:20-28.

8. Sindou M. and Alvernia J.E. (2006): Results of attempted radical tumor removal and venous repair in 100 consecutive meningiomas involving the major dural sinuses, J Neurosurg; 105:514-525.

9. Alvernia J.E. and Sindou M. (2008): Parasagittal Meningiomas, Meningiomas: Diagnosis, Treatment and Outcome, Lee J. H. (ed.); 32: 309- 317.

10. Sindou M. (2009): Meningiomas involving the major dural sinuses: Management of the sinus invasion, Practical Handbook of Neurosurgery from Leading Neurosurgeon, Sindou M. (ed.); volume2: 169-180.

11. Sindou M. and Alvernia J.E. (2011): Surgical Management of the Cerebral Venous Sinuses, Al-Mefty'sMeningiomas, 2nd ed., DeMonte F., McDermott M. W. and Al- Mefty O. (eds.); 37:356-363.

12. Munakomi S., Chaudhary P., Bhattarai B., et al. (2016): Parasagittal meningioma involving the superior sagittal sinus: A case report and literature review of its management algorithm, EMJ Oncol; 4(1):xx-xx.

13. Pires de Aguiar P.H., Aires R., Maldaun M.V., et al. (2010): Is sagittal sinus resection in falcine meningioma a factor of bad surgical outcome? SurgNeurolInt; 1:64.

14. DiMeco F., Li K.W., Casali C., et al. (2004): Meningioma invading the superior sagittal sinus: surgical experience in 108 cases, Neurosurgery; 55(6):1263-1272.

15. Pettersson-Segerlind J., Orrego A., Lonn S., et al. (2011): Long-Term 25-Year Followup of Surgically Treated Parasagittal Meningiomas, World Neurosurgery; 76, 6:564-571.
16. ElBadry A. and Abdelazeez A. (2018): Parasagittal Meningioma Surgery,Romanian Neurosurgery; XXXII 3: $426-442$.

17. Richard S. A., Zheng S., Xuehua X, et al. (2019): A giant invasive parasagittal meningioma with recurrent seizures in a young female: A case report and review of literature, Interdisciplinary Neurosurgery; 15:41-46.

18. Oh I.H., Park B.J., Choi S.K., et al. (2009): Transient Neurologic Deterioration after Total Removal of Parasagittal Meningioma Including Completely Occluding Superior Sagittal Sinus, J Korean NeurosurgSoc; 46:71-73.

19. Ricci A., Di Vitantonio H., DePaulis D., et al. (2017): Parasagittal meningiomas: Our surgical experience and the reconstruction technique of the superior sagittal sinus, SurgNeurolInt; 8:1.

20. Raza S.M., Gallia G.L., Brem H., et al. (2010): Perioperative and Long-term Outcomes From the Management of Parasagittal Meningiomas Invading the Superior Sagittal Sinus, Neurosurgery; 67:885-893.

21. Caroli E., Orlando E.R., Mastronardi L., et al. (2006): Meningiomas infiltrating the superior sagittal sinus: surgical considerations of 328 cases, Neurosurg; 29:236-241.

22. d'Avella E., VOlpin F., Manara R., et al. (2013): Indocyanine green videoangiography (ICGV)-guided surgery of parasagittal meningiomas occluding the superior sagittal sinus (SSS), ActaNeurochir; 155:415-420.

23. Gatterbauer B., Gevsek S., Hoftberger R., et al. (2017): Multimodal treatment of parasagittal meningiomas: a single-center experience, J Neurosurgery; 127:12491250.

24. Black P.M., Morokoff A.P. and Zauberman J. (2008): Surgery of extra-axial tumors of the cerebral convexity and midline, Neurosurgery; 62, 6:1115-1123. 
Hisham H. Nofal, et al.,

25. Brotchi J. (2014): Should we pursue superior sagittal sinus grafting in parasagittal meningioma in 2013?, World Neurosurg; 82:325-6.

26. Girvigian M.R., Chen J.C.T., Rahimian J., et al. (2008): Comparison of Early complications for Patients with Convexity and Parasagittal Meningiomas Treated with Either Stereotactic Radiosurgery or Fractionated Stereotactic Radiotherapy, Neurosurgery; 62:19-28.

27. Shim Y and Lee S.H. (2016): Failed First Craniotomy and Tumor Removal of Parasagittal Meningioma with Sever Peritumoral Brain Edema, Brain Tumor Res Treat; 4(2): 124-127.

28. Mantovani A., Di Maio S., Ferreira M., et al. (2014): Management of meningiomas invading the major dural venous sinuses: operative technique, results, and potential benefit for higher grade tumors, World Neurosurg; 82: 455-467.
29. Huo W.Y., Li L. and Zhang Y.F. (2004): Resection of recurrent parasagittal meningiomas with complete obstructed superior sagittal sinus, International Congress Series; 1259: 53-57.

30. Sughrue M.E., Rutkowski M.J., Shangari G., et al. (2011): Results with judicious modern neurosurgical management of parasagittal and falcine meningiomas. Clinical article, J Neurosurg.; 114(3):731-7.

31. Black P.M. and Zauberman S. (2010): Parasagittal and falxmeningiomas, Meningiomas: a comprehensive text, Palmir M. N., Black P. M., Fallbusch R. (Eds). China: Saunders; 349-354.

32. Tomasello F., Conti A., Cadrali S., et al. (2013): Venous preservation-guided resection: a changing paradigm in parasagittal meningioma surgery, $\mathrm{J}$ Neurosurg; 119 (1): 74-81 


\section{محاولة الاستئصال الجذري للأورام السحائية المجاورة للجيب الوريدي السهمي العلوى: المخاطر والمنافع}

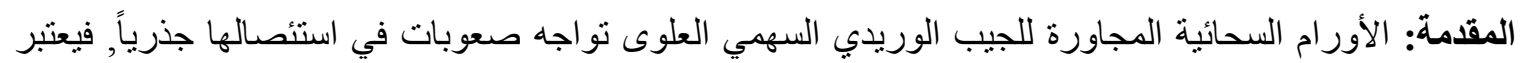

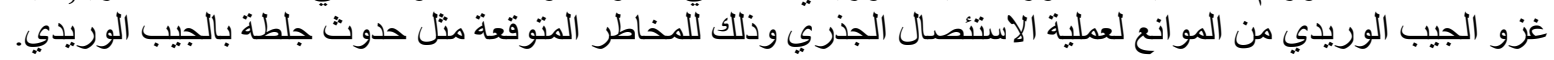

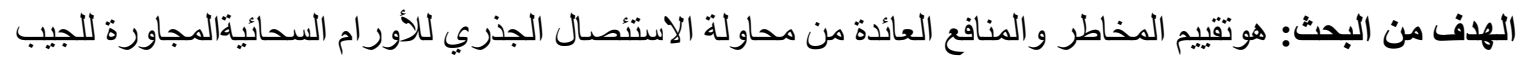

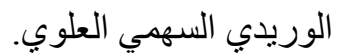

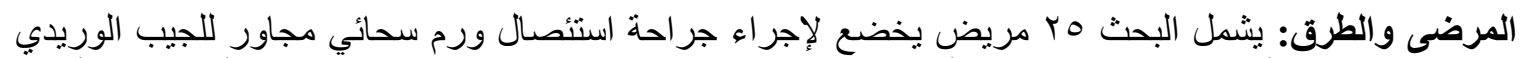

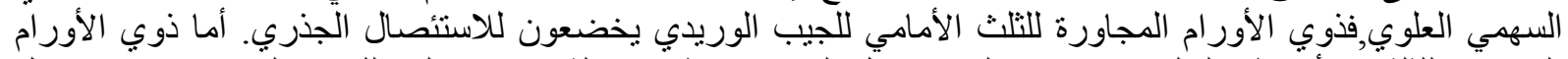

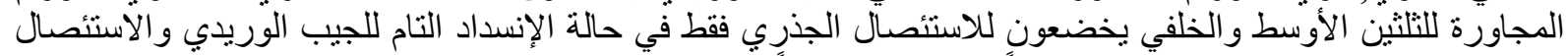
الجزئي في حالة غزو الجيب الاوسط الوريدي جزئياً و عدم انسداده كلياً.

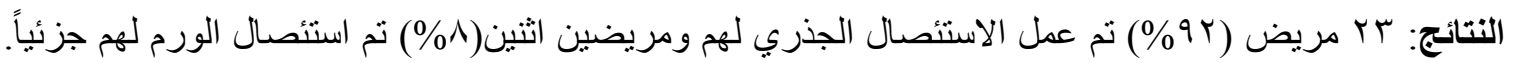

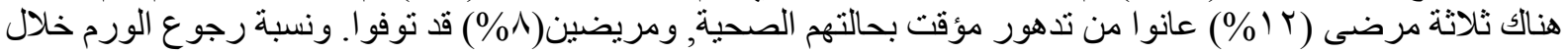
سنتين من المتابعة كانت (0\%).

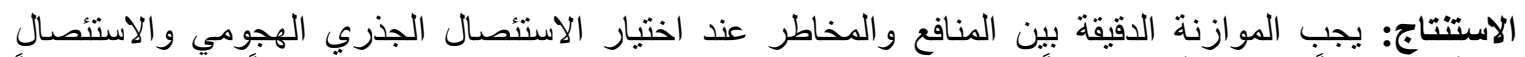

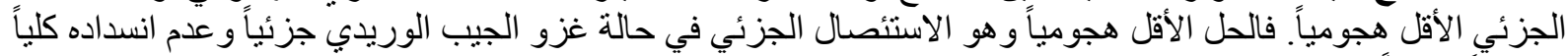
يعد حلاً مناسباً. 